Check for updates

Cite this: Mater. Adv., 2020, 1, 3545

Received 4th September 2020, Accepted 1st November 2020

DOI: $10.1039 / \mathrm{d} 0 \mathrm{ma} 00678 \mathrm{e}$

rsc.li/materials-advances

\title{
Study of ferro- and anti-ferroelectric polar order in mesophases exhibited by bent-core mesogens $\dagger$
}

\author{
Susanta Chakraborty, (D) a Malay Kumar Das, (D) *a Christina Keith ${ }^{\mathrm{b}}$ and \\ Carsten Tschierske (iD ${ }^{b}$
}

\begin{abstract}
The polar nature of three pure homologous bent-core compounds derived from 4-cyanoresorcinol bisbenzoates as a central core unit were studied based on dielectric spectroscopy measurements and electro-optical investigation. All these compounds exhibited a highly correlated nematic phase $\left(N_{\text {Cybc }}\right)$ followed by a phase (CybC) comprising elongated but not completely fused strings of cybotactic clusters. Additionally, the higher homologous compounds exhibited one or more tilted smectic phases $\left(\mathrm{SmC}_{(\mathrm{I})}, \mathrm{SmC}_{(\mathrm{II})}\right)$. Based on all the investigated results, the $N_{\text {Cybc }}$ phase was found to be quite different from the usual nematics, consisting of tiny polar clusters, which in effect revealed a ferroelectric polarization within the medium. Moreover, the lower temperature SmC phases $\left(\mathrm{SmC}_{(\mathrm{I})}\right.$ and $\mathrm{SmC}_{(\mathrm{III})}$ characterized an anti-ferroelectric type of molecular dipolar ordering in adjacent layers. The intermediate $\mathrm{CybC}$ phase accomplished the transition from the ferroelectric-type $N_{\text {cybc }}$ phase to the anti-ferroelectric type of the $S m C_{(I)}$ phase, where the cybotactic clusters were elongated. The $S m C_{(I I)}$ phase was a SmC phase with an enhanced packing density in comparison to the $\mathrm{SmC}_{(\mathrm{I})}$ phase, which seems like a more solid-like state or glassy state. The field reversal polarization technique and the simultaneous observation of the optical textures corroborated the polar nature of the mesophases. These outcomes were explained by considering the structural changes of the molecules by increasing the chain length and the combined effect of their association in the dielectric parameters of the respective mesophases. Finally, it was concluded that the $S m C_{(I)}$ phase should be designated as $\mathrm{SmC}_{\mathrm{S}} \mathrm{P}_{\mathrm{A}}$ phase $\left(C_{S}\right.$ stands for a synclinic-type of molecular organization and $P_{A}$ corresponds to an antiferroelectric ordering of the polar orientation in neighboring layers), where the $\mathrm{SmC}_{(\mathrm{II})}$ phase was characterized by a quite solid-like state or close-packed SmC phase with a similar type of synclinic anti-ferroelectric ordering ( $\mathrm{SmC}^{\prime}{ }_{\mathrm{S}} \mathrm{P}_{\mathrm{A}}$ phase).
\end{abstract}

\section{Introduction}

Investigations of the structural property correlation in liquid crystals (LC) have achieved a new platform subsequent to the discovery of bent-core (BC) mesogens. Encompassing the unique conformational features compared to the usual calamitic molecules, BC mesogens are enriched with exotic mesomorphic behaviors, such as giant flexo-electricity, ${ }^{1,2}$ unique rheological properties, ${ }^{3,4}$ a considerable Kerr effect, ${ }^{5}$ an unpredictable behavior of the electro-convection patterns, ${ }^{6-8}$ a polar switching behavior, and structural layer chirality. ${ }^{9-12}$ Owing to all these unique properties, $\mathrm{BC}$ compounds are quite interesting from both the application point of view and understanding the structural

\footnotetext{
${ }^{a}$ Department of Physics, University of North Bengal, Siliguri-734 013, India. E-mail:mkdnbu@yahoo.com

${ }^{b}$ Martin-Luther-Universität Halle-Wittenberg, Institut für Chemie, Physikalische Chemie, Halle, Germany

$\dagger$ Electronic supplementary information (ESI) available. See DOI: 10.1039/ d0ma00678e
}

property correlation. ${ }^{13-19}$ Additionally, the signature of a fascinating polar behavior in the banana or $\mathrm{B}$ phases as well as experimental evidence of significant ferro- and anti-ferroelectric ordering are other intriguing aspects of these BC materials. Moreover, in BC compounds, different mesophases exhibit unusual and quite rare characteristics depending on the magnitude and position of the bend-angle, the size of the molecules as well as the influence of the terminal chain, linking groups, number of aromatic rings, transverse molecular polarity, etc. ${ }^{20-22}$ Therefore, significant attention has been paid by researchers over the last few decades to the design, synthesis, and characterization of new BC materials with striking features. Extensive efforts have also been employed toward the understanding or overview of the effective mesomorphic properties linked with the molecular conformers and the remarkable improvements of the physical properties.

In contrast to a variety of smectic-like phases (banana or $\mathrm{B}$ phases), the divulgence of a stable nematic phase in these $\mathrm{BC}$ compounds is quite challenging and unveils a fascinating new domain in the branch of thermotropic LCs. Smectic-like strong 
short-range local ordering in the nematic phase (namely the cybotactic nematic mesophase, $N_{\text {CybC }}$ ) has been reported ${ }^{23-33}$ in a number of cases. Later investigation of a bent-core compound based on 1,2,4-oxadiazole as a central unit demonstrated a ferroelectric-like response in the nematic phase due to the existence of smectic-like polar cybotactic clusters. ${ }^{32}$ Keith et al. reported a homologous series of bent-core compounds having a broad range of cybotactic nematic phases along with higher ordered smectic phases and put forward an idea about the molecular orientations within these mesophases. ${ }^{33}$ Chirality in layers was also observed for BC mesogens ${ }^{34}$ due to the combined effect of a molecular tilt and the polar vector of the molecules in adjacent layers, though they are achiral in nature. ${ }^{35}$ In a majority of BC mesogens, the chirality is an often encountered phenomenon, such as in $N_{\mathrm{CybC}}{ }^{*}$ (chiral cybotactic nematic) ${ }^{36}$ and the recently discovered $N_{\text {tb }}$ (twist-bent nematic) phase (chirality emerges as an induced feature). ${ }^{37,38}$ Apart from the conventional calamitic compounds, such exciting characteristics observed in $\mathrm{BC}$ compounds arise due to the steric hindrance induced by the bent geometry, which distorts the symmetry of these molecules.

Based on determining the frequency-dependent complex permittivity, the study of dielectric spectroscopy has emerged as an attractive technique for investigating the dielectric and molecular properties of BC liquid crystals (LCs). Over the past few decades, enormous efforts have been devoted to characterizing the relaxation modes in different LC systems, comprising calamitic, ${ }^{39-41}$ discotic, ${ }^{42}$ T-shaped, ${ }^{43}$ and chiral $^{44-46}$ molecules, and also some LC systems doped with nanoparticles and porous media. ${ }^{47-50}$ Usually, the calamitic nematogens are found to exhibit three dielectric relaxation modes in the high-frequency range, ${ }^{40}$ while a number of relaxation modes at the lower frequency region have been explored in some $\mathrm{BC}$ systems compared to calamitics. ${ }^{51,52}$ Till now, different experimental verifications have confirmed that the presence of smectic $C(\mathrm{SmC})$-type polar nanoclusters is responsible for the occurrence of such unusual behavior $^{53}$ and ferroelectric-like switching has been observed in these nematic phases. ${ }^{53,54}$ Therefore, the presence of these types of unusual mesophases and a proper understanding of the appearance of the polar nature in these $\mathrm{BC}$ compounds is quite motivating to perform this dielectric spectroscopy study in a broad sense.

In this paper, we focus on the dielectric spectroscopy and the electro-optical investigation of three pure achiral bent-core compounds of a homologous series derived from 4-cyanoresorcinol bisbenzoates. The manifestation of the relaxation modes throughout the entire mesomorphic regions has been discussed in light of the associative molecular behavior both in planar and homeotropic alignments. A simultaneous comparison of the relaxation modes was also performed for all the homologs in accordance with the variation of temperature and chain length as well as the strength of the dipoles in respective mesophases. The obtained outcomes are interpreted herein in terms of the molecular structure, a correlation of the dipoles, and simultaneous observation of the response of the relaxation modes when applying external DC bias voltage. Additionally, we measured the field reversal switching behavior to validate the polar nature of the mesophases, which implied that the nematic phase was a ferroelectric type while both the lower temperature $\mathrm{Sm} C$ phases $\left(\mathrm{Sm}_{(\mathrm{I})}\right.$ and $\left.\mathrm{Sm} C_{(\mathrm{II})}\right)$ were anti-ferroelectric type.

\section{Experimental}

\subsection{Materials}

The investigated three homologous bent-core compounds were symmetric in shape and they were derived from a 4-cyanoresorcinol bisbenzoates-based central unit having terminally substituted alkyl chains. ${ }^{33,55}$

The structural formula and phase-transition scheme of these homologs $(\mathbf{1} / \mathbf{7}, \mathbf{1} / \mathbf{9}$, and $\mathbf{1 / 1 0})$ are shown below and their synthesis has been reported elsewhere. ${ }^{33}$ All these compounds exhibited a highly correlated nematic phase $\left(N_{\mathrm{Cybc}}\right)$ over a wide temperature range followed by a LC phase (CybC) comprising elongated but not completely fused strings of cybotactic clusters. In addition, the higher homologs (1/9 and 1/10) exhibited one or more tilted smectic phases $\left(\mathrm{SmC}_{(\mathrm{I})}, \operatorname{Sm} C_{(\mathrm{II})}\right)$. Both compounds 1/9 and 1/10 exhibited a negative value of dielectric anisotropy, while compound 1/7 revealed an inversion from positive to negative dielectric anisotropy in the $N_{\text {Cybc }}$ phase. ${ }^{55}$

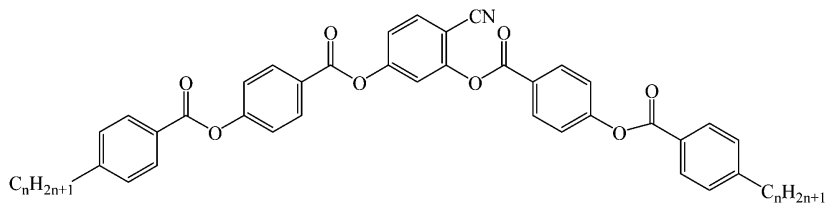

Phase sequences for the compounds during the cooling cycle (the transition temperatures are from the POM and optical transmission measurement study ${ }^{55}$ ):

Compound 1/7 $(n=7)$ : CybC $313.3 \mathrm{~K} N_{\text {CybC }} 383 \mathrm{~K} \mathrm{I}$

Compound 1/9 $(n=9): \mathrm{Sm}_{(\mathrm{I})} 325.4 \mathrm{~K}$ CybC $333.5 \mathrm{~K} N_{\text {CybC }}$ $378.6 \mathrm{~K} \mathrm{I}$

Compound 1/10 $(n=10): \mathrm{Sm}_{(\mathrm{II})} 330.1 \mathrm{~K} \mathrm{Sm} C_{(\mathrm{I})} 341.6 \mathrm{~K} \mathrm{CybC}$ $351.6 \mathrm{~K} N_{\text {CybC }} 377.6 \mathrm{~K} \mathrm{I}$

\subsection{Dielectric spectroscopy study}

Different dielectric parameters were explored for the investigated compounds using an impedance analyzer Agilent 4294A in the frequency range of $40 \mathrm{~Hz}-15 \mathrm{MHz}$ with a maximum $\mathrm{AC}$ voltage of $0.5 \mathrm{~V}$ (RMS) to avoid nonlinear responses. Samples were filled into ITO-coated LC cells (procured from AWAT PPW, Warsaw, Poland) with a thickness of $\sim 9 \mu \mathrm{m}$ having both planar (HG) and homeotropic (HT) configurations. The LC cells were placed inside a hot/cool stage (INSTEC HCS 302), which was controlled by INSTEC mK1000 programmable temperature controller having a maximum temperature resolution of $0.001{ }^{\circ} \mathrm{C}$. During cooling from the isotropic phase, the real $\left(\varepsilon^{\prime}\right)$ and the imaginary $\left(\varepsilon^{\prime \prime}\right)$ parts of the complex dielectric permittivity were measured at each temperature (kept stabilized for $5 \mathrm{~min}$ at each temperature) throughout the entire mesomorphic range at an interval of $1 \mathrm{~K}$. The temperature-dependent complex dielectric permittivity, $\varepsilon^{*}(f)$, can be well described by the Havriliak-Negami $(\mathrm{H}-\mathrm{N})$ equation with an additional 
term standing for the low-frequency conductivity contribution as follows: ${ }^{56,57}$

$$
\varepsilon^{*}(f)=\varepsilon_{\infty}+\sum_{k=1}^{N} \frac{\delta \varepsilon_{k}}{\left[1+\left(\mathrm{i} 2 \pi f \tau_{k}\right)^{\alpha_{k}}\right]^{\beta_{k}}}-\frac{i \sigma_{0}}{\varepsilon_{0}(2 \pi f)^{S}}
$$

where $\delta \varepsilon_{k}$ is the dielectric strength, $\varepsilon_{\infty}$ is the high-frequency limit of the permittivity, $\tau_{k}\left(1 / 2 \pi f_{k}\right)$ is the relaxation time, $f$ is the corresponding relaxation frequency, $\alpha_{k}$ and $\beta_{k}$ are the shape parameters (can be between 0 and 1) describing the symmetric and non-symmetric broadness of the dielectric dispersion curve, respectively, and $k$ is the number of relaxation processes. However, $\sigma_{0}$ is related to the DC conductivity and $S$ is a fitting parameter responsible for the slope of the conductivity. The obtained real and imaginary parts $\left(\varepsilon^{\prime}\right.$ and $\left.\varepsilon^{\prime \prime}\right)$ of the complex permittivity can be fitted with Havriliak-Negami $(\mathrm{H}-\mathrm{N})$ fitfunctions $^{57,58}$ given below:

$$
\begin{aligned}
& \varepsilon^{\prime}= \varepsilon_{\infty} \\
&+\sum_{k=1}^{N} \frac{\delta \varepsilon_{k} \cos (\beta \theta)}{\left[1+\left(2 \pi f \tau_{k}\right)^{2 \alpha_{k}}+2\left(2 \pi f \tau_{k}\right)^{\alpha_{k}} \cos \left(\alpha_{k} \pi / 2\right)\right]^{\beta_{k} / 2}} \\
& \varepsilon^{\prime \prime}=\frac{\sigma_{0}}{\varepsilon_{0}(2 \pi f)^{S}} \\
&+\sum_{k=1}^{N} \frac{\delta \varepsilon_{k} \sin (\beta \theta)}{\left[1+\left(2 \pi f \tau_{k}\right)^{2 \alpha_{k}}+2\left(2 \pi f \tau_{k}\right)^{\alpha_{k}} \cos \left(\alpha_{k} \pi / 2\right)\right]^{\beta_{k} / 2}}
\end{aligned}
$$

with

$$
\theta=\tan ^{-1}\left[\frac{\left(2 \pi f \tau_{k}\right)^{\alpha_{k}} \sin \left(\alpha_{k} \pi / 2\right)}{1+\left(2 \pi f \tau_{k}\right)^{\alpha_{k}} \cos \left(\alpha_{k} \pi / 2\right)}\right]
$$

\subsection{Electro-optical investigation}

Electro-optical investigations for the three investigated bentcore compounds were carried out in combination with the field reversal polarization technique ${ }^{59}$ by applying a triangular wave AC input voltage (amplified by 20 times) and by observation of the optical texture (by using the square wave of low frequency) under a crossed polarizing optical microscope (POM) BANBROS BPL400 B attached with a CCD camera Moticam 580 (5.0 MP). An absolute voltage of $180 \mathrm{~V}_{\mathrm{pp}}, 20 \mathrm{~Hz}$ was applied with a proper resistive circuit to the sample filled ITO-coated commercial cells, both in planar and homeotropic orientations. Hence, an effective voltage of about $\pm 20 \mathrm{~V}$ acted per $\mu \mathrm{m}$ on the cell, which drove a current through the material. The output switching current was acquired by using an Agilent DSOX2000A oscilloscope at a temperature interval of $1 \mathrm{~K}$.

\section{Results and discussion}

\subsection{Dielectric spectroscopy study}

The frequency-dependent real $\left(\varepsilon^{\prime}\right)$ and imaginary $\left(\varepsilon^{\prime \prime}\right)$ parts of the complex permittivity for compound $\mathbf{1 / 7}$ (at a particular temperature of $348 \mathrm{~K}$ ) are presented in Fig. 1(a) and (b) for the planar (HG) and homeotropic (HT) alignments, respectively. The corresponding temperature dependence of
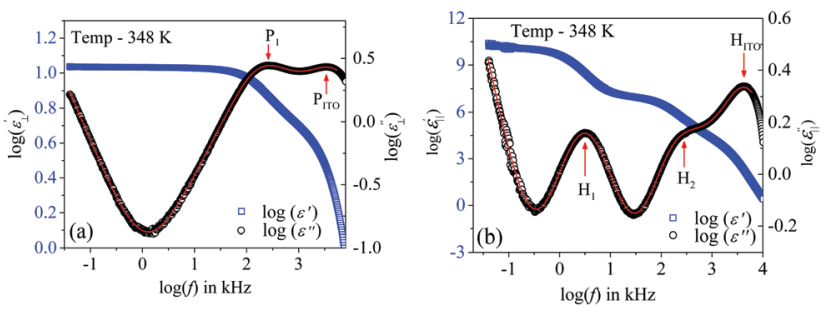

Fig. 1 Frequency dependence of the real $\left(\varepsilon^{\prime}\right)$ and imaginary $\left(\varepsilon^{\prime \prime}\right)$ parts of the permittivity for compound 1/7: in (a) HG or planar and (b) HT or homeotropic sample configurations. Red solid curves represent the fit to the data points with eqn (3).

the relaxation frequency $\left(f_{\mathrm{R}}\right)$ for the different relaxation modes is illustrated in Fig. 2(a and b) for both cell configurations, while the associated dielectric strengths $(\delta \varepsilon)$ are shown in Fig. 2(c and d).

The obtained dielectric spectra in Fig. 1(a) for the HG cell clearly indicated two relaxation peaks, one marked as $\mathrm{P}_{1}$ that appeared in a few $\mathrm{kHz}$ ranges and a high-frequency peak marked as $\mathrm{P}_{\text {ITO }}$ that was independent of temperature and arose due to the influence of ITO resistance in series with the cell capacitance. Conversely, in the case of the HT cell, the corresponding relaxation modes are presented in Fig. 1(b), indicating a high-frequency peak $\mathrm{H}_{\text {ITO }}$ along with two temperature-dependent peaks $\left(\mathrm{H}_{1}, \mathrm{H}_{2}\right)$ appearing at the lower frequency side of $\mathrm{H}_{\text {Iто }}$. Noticeably, the $\mathrm{P}_{1}$ mode in the $\mathrm{HG}$ cell had a smaller value of dielectric strength $(\delta \varepsilon)$ throughout the whole cybotactic nematic $\left(N_{\mathrm{CybC}}\right)$ phase. On the other hand, the $\mathrm{H}_{1}$ mode in the HT cell appeared at a lower frequency range with a smaller value of $\delta \varepsilon$ and was weakly sensitive to the externally applied bias field. The reason behind the appearance of the $\mathrm{P}_{1}$ and $\mathrm{H}_{1}$ modes might be regarded as the rotation of the molecules around their long and short axes, respectively. ${ }^{60}$ In the case of the transverse component ( $\mathrm{HG}$ cell), the effect of the molecular rotation around the long axis led to a highfrequency relaxation peak, while in the longitudinal component (HT cell), the same occurred about the short axis subjected to a low-frequency relaxation peak. Similar observations were reported by Jang et al. ${ }^{60}$ both in planar and homeotropic orientations. The extracted experimental values of the relaxation frequency $\left(f_{\mathrm{R}}\right)$ for the present compound agreed quite well with the reported value ${ }^{60}$ in both orientations, as represented in Fig. 2( $\mathrm{a}$ and b). However, in addition to the $\mathrm{H}_{1}$ relaxation mode in the HT cell, the present investigation showed a second mode $\left(\mathrm{H}_{2}\right)$ in the higher frequency region. Upon lowering the temperature, the value of the relaxation frequency $\left(f_{\mathrm{R}}\right)$ for this mode progressively decreased toward the lower frequency region throughout the $N_{\text {Cybc }}$ phase. Moreover, the values of $f_{\mathrm{R}}$ were found to be nearly equal to those for the $\mathrm{P}_{1}$ mode in the planar configuration and also revealed a weak dependence on the applied biasing field. Hence, it can be assumed that the superposition of different independent rotations of polar molecules around their long axis or around the principle director implements this relaxation mode. Earlier investigations by Tadapatri et al. for a similar type of molecule with 

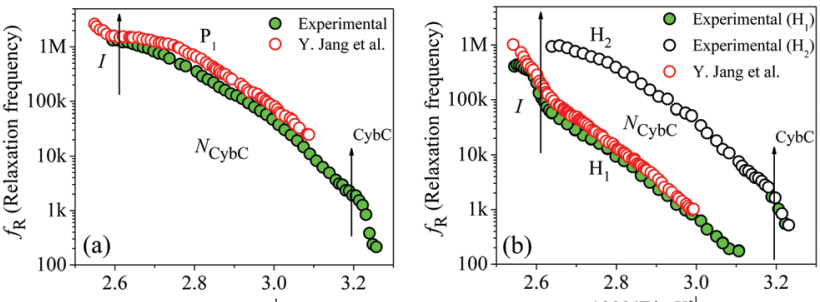

$1000 / T$ in $\mathrm{K}^{-1}$
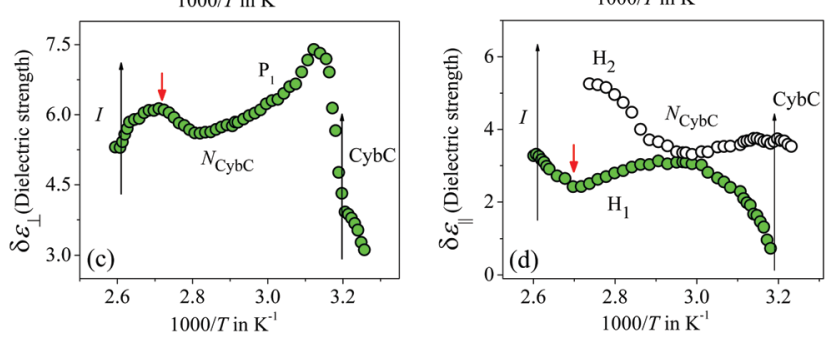

Fig. 2 Temperature dependence of the relaxation frequency $\left(f_{\mathrm{R}}\right)$ and dielectric strength $(\delta \varepsilon)$ for compound 1/7: (a and c) in $\mathrm{HG}$ alignment and ( $b$ and $d$ ) in HT alignment. Vertical arrows define the corresponding phasetransition temperatures.

alkoxy terminal chain also support the present outcomes. ${ }^{61,62}$ This type of high-frequency relaxation mode in longitudinal components appears in the $\mathrm{GHz}$ range for the usual calamitics but a downshift of this mode in the bent-core compound may be attributed to the molecular size and very high viscosity of the sample. A quite analogous identification of three relaxation peaks $\left(\mathrm{H}_{1}, \mathrm{H}_{2}\right.$ in $\mathrm{HT}$ cell, and $\mathrm{P}_{1}$ in $\mathrm{HG}$ cell) has also been observed in some bent-core nematic as well as in mixtures with calamitics. ${ }^{63-65}$ Interestingly, in the present investigation, the dielectric strength $(\delta \varepsilon)$ for the modes $\mathrm{P}_{1}$ and $\mathrm{H}_{1}$ was found to demonstrate an anomalous behavior at a region below $\sim 15 \mathrm{~K}$ from the isotropic-nematic (I- $N_{\text {CybC }}$ ) phase transition, as shown in Fig. 2(c and d). The $\delta \varepsilon$ value initially increased in the HG cell, while it was reduced in the HT cell followed by the I $-N_{\text {Cybc }}$ phase transition. Surprisingly, near the temperature $365 \mathrm{~K}$ (marked with the red arrow), the $\delta \varepsilon$ value in both cases revealed a kink and followed the opposite pattern thereafter. Previous investigation of this compound also revealed an inversion of positive to negative dielectric anisotropy at $\sim 18 \mathrm{~K}$ below the $\mathrm{I}-N_{\text {Cybc }}$ phase-transition temperature. ${ }^{55}$ Due to the presence of $\mathrm{SmC}$-type polar nanoclusters in the nematic phase, the mutual alignment of these clusters leads to such a behavior. However, this inversion of dielectric anisotropy is also dependent on the frequency and the nature of the corresponding crossover frequency is a highly non-Arrhenius type at lower temperature. ${ }^{60,66}$ Recently, Jang et al. explained that inversion by assuming the values of the anisotropic Kirkwood correlation factors $\left(g_{\|}\right.$and $\left.g_{\perp}\right)$ were not equal to 1 , rather $g_{\|}$ decreased and $g_{\perp}$ increased from unity, i.e., $g_{\|}<1$ and $g_{\perp}>1$. ${ }^{66}$

The frequency-dependent imaginary $\left(\varepsilon^{\prime \prime}\right)$ part of the complex permittivity for the second homologous compound $\mathbf{1 / 9}$ is shown in Fig. S3 in the ESI. $\dagger$ The corresponding temperaturedependent relaxation frequencies $\left(f_{\mathrm{R}}\right)$ and the dielectric strengths $(\delta \varepsilon)$ are plotted in Fig. $3(\mathrm{a}-\mathrm{d})$ for the HG and HT orientations, respectively.
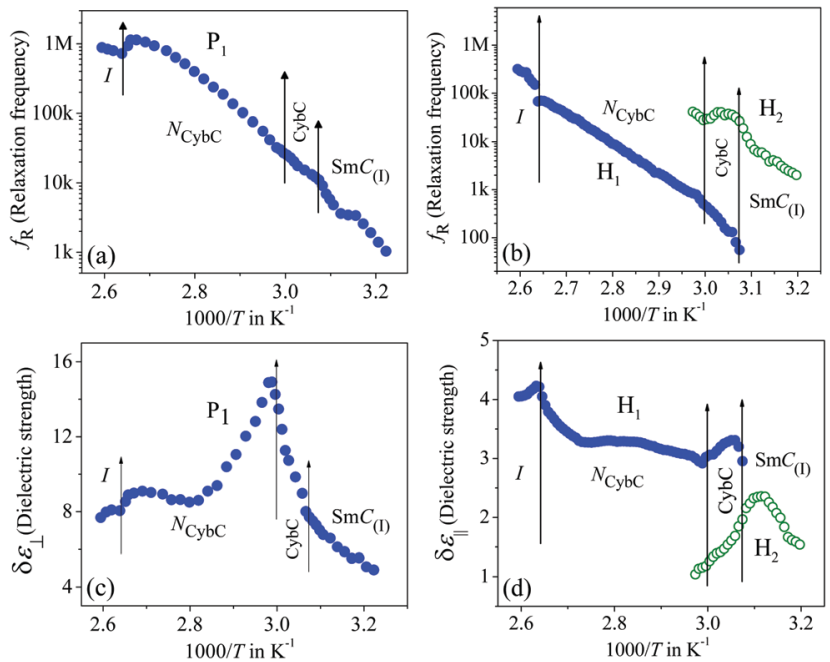

Fig. 3 Temperature dependence of the relaxation frequency $\left(f_{\mathrm{R}}\right)$ and dielectric strength $(\delta \varepsilon)$ for compound 1/9: in (a and c) HG and (b and d) HT alignments. Vertical arrows define the corresponding phase-transition temperatures.

In this case, the planar-oriented compound $\mathbf{1} / \mathbf{9}$ was characterized by a single relaxation peak $\left(\mathrm{P}_{1}\right)$. On the other hand, in the HT cell, the dielectric modes were portrayed by two relaxation peaks: $\mathrm{H}_{1}$ and $\mathrm{H}_{2}$. The $\mathrm{H}_{1}$ mode appeared at a frequency of about $100 \mathrm{kHz}$ and was found to decrease throughout the $N_{\mathrm{CybC}}$ phase with lowering the temperature; while the other mode $\left(\mathrm{H}_{2}\right)$ arose near the $N_{\mathrm{CybC}}-\mathrm{CybC}$ phase transition but at a relatively higher frequency region than the $\mathrm{H}_{1}$ mode. A closer look at the temperature variation of $f_{\mathrm{R}}$ for the $\mathrm{P}_{1}$ mode suggested the almost same variation as observed in the planaraligned compound $\mathbf{1 / 7}$. The dielectric strength $(\delta \varepsilon)$ of this peak was strongly dependent on the temperature, i.e., it gradually increased its magnitude in the nematic phase with the decreasing temperature. Further lowering the temperature, the value of $\delta \varepsilon$ decreased sharply in the $\operatorname{Sm} C_{(\mathrm{I})}$ phase via the CybC phase. A similar type of observation for the dielectric strength was reported by Eremin et al. for the transition to a para-electric to anti-ferroelectric $\mathrm{SmC}$ phase transition for a bent-core compound. ${ }^{67}$ Since, the $N_{\text {Cybc }}$ phase comprised a number of small-sized cybotactic clusters with the SmC-type layer structure, this corresponded to a strong short-range correlation among the molecules and the cluster size was elongated by lowering the temperature. ${ }^{33}$ Thus, the appearance of this mode could be assigned as due to the rotation of molecules within the clusters around the long axis of the director in the nematic phase. However, the presence of a transverse dipole moment of the molecules essentially affected this mode in the $\mathrm{SmC}_{(\mathrm{I})}$ phase and this process was related to a collective relaxation of the dipoles. It can thus be considered that the short-range polar correlation now became anti-parallel in the $\mathrm{SmC}_{(\mathrm{I})}$ phase. The CybC phase is a phase comprising elongated but not completely fused strings of cybotactic clusters and therefore, the antiparallel dipolar alignments were observed to be initiated from the $N_{\mathrm{CybC}}-\mathrm{CybC}$ phase transition. Although, compound 1/9 
possessed a larger molecular size and dimensions of the cluster in comparison to that of compound $\mathbf{1 / 7}$, the temperaturedependent variation of the cluster size as well as the molecular tilt played significant roles in the entire $N_{\text {Cybc }}$ mesophase. The tilt angle of these molecules was enhanced from $15^{\circ}$ in the $N_{\text {CybC }}$ phase to $32^{\circ}$ in the perfectly aligned $\operatorname{Sm}_{(\mathrm{I})}$ phase through the intermediate CybC phase in which the molecular tilt angle was $28^{\circ} .33$ Therefore, the assembly of molecular dipole moments associated with $\mathrm{SmC}$-type polar clusters in the $N_{\text {Cybc }}$ phase formed a short-range ferroelectric type ordering, which thereby increased the strength of the relaxation modes by decreasing the temperature followed by the elongation of the cluster size. Consequently, the value of $\delta \varepsilon$ was enhances gradually in the $N_{\text {CybC }}$ phase. With further decreasing the temperature, clusters were fused into elongated ribbon-like aggregates in the CybC phase and the dipole moments were oriented in such a way that an anti-ferroelectric type of ordering of the dipoles developed in adjacent layers. The strong dipole-dipole interaction favored aligning the molecular dipole moments in adjacent layers with an anti-parallel ordering. This anti-ferroelectric type of orientation continued by itself throughout the $\mathrm{Sm}_{(\mathrm{I})}$ phase, which caused an effective decrease in the $\delta \varepsilon$ value in the CybC and $\mathrm{Sm}_{(\mathrm{I})}$ phases. An almost identical type of behavior was observed by Guo et al. for a bent-core compound at the transition from the $\operatorname{Sm}_{A} \mathrm{P}_{\mathrm{R}}$ phase to

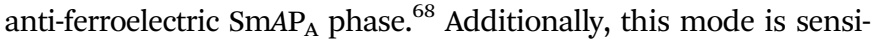
tive to the external bias field. From Fig. 4(a), clear evidence of the strengthening of the $\mathrm{P}_{1}$ mode was found by increasing the bias field without any measurable change in $f_{\mathrm{R}}$. This indicated that this mode $\left(\mathrm{P}_{1}\right)$ developed due to the molecular rotation about the long axis and additionally was influenced by the local anti-ferroelectric ordering of the molecular dipoles in adjacent layers of the $\mathrm{SmC}_{(\mathrm{I})}$ phase. A complete realization of this issue has been drawn from the field-induced polarization technique as described later. With a further increase in the field strength, the trivial appearance of an additional peak $\left(\mathrm{P}_{2}\right)$ was seen in the $\mathrm{SmC}_{(\mathrm{I})}$ phase at a lower frequency side compared to that of the $\mathrm{P}_{1}$ mode. This implies that there also existed an additional motion of the molecules around the short axis or bow axis, and also that it has an influence on the local polar ordering and therefore, apparently could be recognized due to the application of external voltage. Nevertheless, in the case of the HT configuration, both the $\mathrm{H}_{1}$ and $\mathrm{H}_{2}$ peaks had a relatively smaller dielectric strength than the $\mathrm{P}_{1}$ mode and a weak temperature dependency. However, a noticeable change in $\delta \varepsilon$
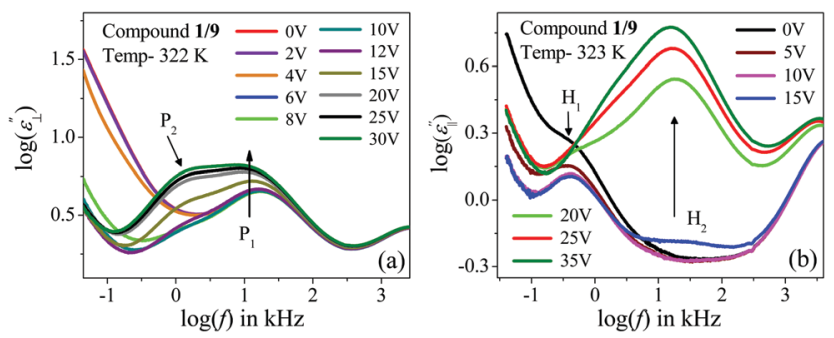

Fig. 4 Variation of the frequency-dependent imaginary $\left(\varepsilon^{\prime \prime}\right)$ part of the permittivity with the bias voltage for compound 1/9: in (a) planar and (b) homeotropic alignment of cells. was found in the CybC and $\operatorname{Sm} C_{(\mathrm{I})}$ phases. The relaxation frequency for the $\mathrm{H}_{1}$ mode was quite similar to that of compound $1 / 7$ in the $N_{\text {Cybc }}$ phase. This mode could also be assigned to the molecular relaxation, which appears due to the end-over-end rotation of molecules around their short axis or bow axis. ${ }^{62}$ The signature of the $\mathrm{H}_{2}$ mode was found from the CybC mesophase at a relatively higher frequency region than for $\mathrm{H}_{1}$ and it extended to the entire $\mathrm{SmC}_{(\mathrm{I})}$ phase. Interestingly, the strength of this mode was highly sensitive to the external bias field, i.e., the value of $\delta \varepsilon$ increased with increasing the bias voltage, while it was very small in the absence of the field, as observed in Fig. 4(b). This mode could be attributed to a relaxation in which anti-ferroelectric domains of the polar molecules in the $\mathrm{SmC}_{(\mathrm{I})}$ phase are transformed to ferroelectric domains by the application of an external DC field, thereby effectively increasing the strength. Fig. 4 implies that the electric field response of the relaxation modes was much stronger in the HT configuration than that in the HG. This demonstrated that the contribution of the effective molecular dipole moment along the field direction in HT alignment was strong compared to in the HG configuration subsequent to the application of bias voltage. Therefore, due to the anti-parallel alignment of the molecular dipoles, the effective dielectric strength initially showed a much smaller value in the absence of the field. With increasing the external field, the dipolar groups tended to reorient progressively in parallel to the field direction, while the long molecular axes remained randomly distributed around the field direction. This resulted in an enhancement of the dielectric strength along the field direction with increasing the field strength. However, in the case of the HG cell, the component of the dipole moment along the field direction was too weak compared to that in HT cell and therefore, it was not so sensitive to the external bias field.

The frequency-dependent imaginary $\left(\varepsilon^{\prime \prime}\right)$ part of the complex permittivity for the higher homolog $\mathbf{1 / 1 0}$ is shown in Fig. S5 in the ESI, $\dagger$ for both cell configurations. The corresponding temperature-dependent relaxation frequencies $\left(f_{\mathrm{R}}\right)$ and the dielectric strengths $(\delta \varepsilon)$ are plotted in Fig. 5(a-d), respectively.

Compound 1/10 in a planar configuration revealed a highfrequency peak $\left(\mathrm{P}_{1}\right)$ in a frequency range identical to the lower homologous compounds, with a relatively large value of $\delta \varepsilon$. During cooling from the isotropic phase, the value of $\delta \varepsilon$ gradually increased in the $N_{\text {CybC }}$ phase and was found to decrease in the following CybC and $\mathrm{SmC}_{(\mathrm{I})}$ phases. This observation was quite similar to the planar-aligned compound 1/9. Moreover, in the $\mathrm{SmC}_{(\mathrm{I})}$ phase, an additional relaxation mode $\left(\mathrm{P}_{2}\right)$ with a very close value of $f_{\mathrm{R}}$ was detected. Upon applying an external bias field, these two modes could be clearly resolved (see Fig. 6(a)). During further reduction of the temperature, the $\mathrm{P}_{1}$ mode persisted over the lower temperature $\mathrm{Sm} C_{(\mathrm{II})}$ phase. Therefore, similar to compound $\mathbf{1} / \mathbf{9}$, the $\mathrm{P}_{\mathbf{1}}$ mode in compound 1/10 could be ascribed to the molecular mode in the $N_{\text {CybC }}$ phase, while in the tilted $\mathrm{SmC}_{(\mathrm{I})}$ phase, the orientation of the molecules were in an anti-parallel fashion with a greater tilt angle, describing a kind of collective process of relaxation. Conversely, in the homeotropic-oriented sample, a single relaxation mode $\left(\mathrm{H}_{2}\right)$ was observed throughout the whole mesomorphic 

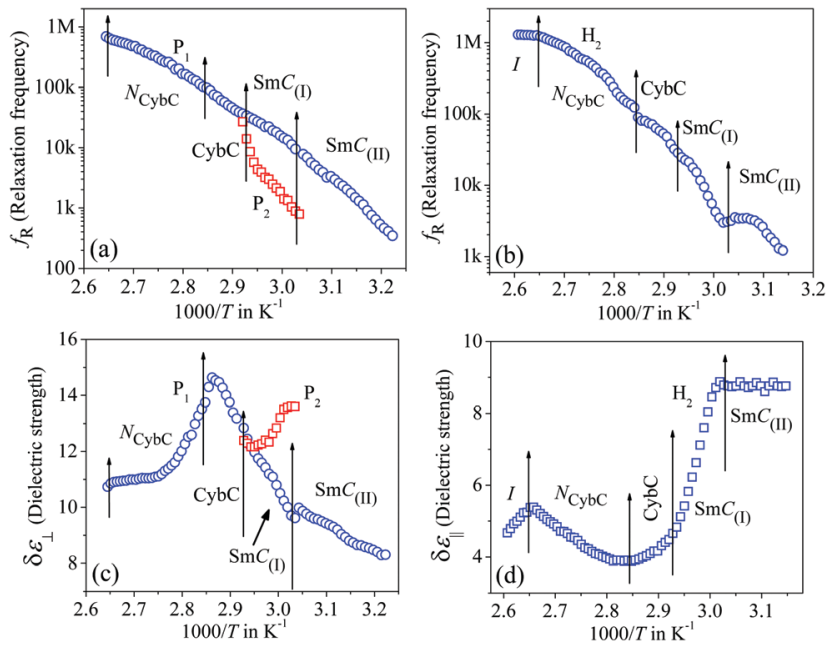

Fig. 5 Temperature dependence of the relaxation frequency $\left(f_{R}\right)$ and dielectric strength $(\delta \varepsilon)$ for compound 1/10: ( $a$ and $c$ ) in planar and (b and d) homeotropic configurations, respectively. Vertical arrows define the corresponding phase-transition temperatures.

regime rather than the two relaxation modes $\left(\mathrm{H}_{1}\right.$ and $\left.\mathrm{H}_{2}\right)$ present in lower homologous compounds (1/7 and 1/9). The strength of this mode was comparatively lower than that of the HG configuration. Although, during cooling, the value of $\delta \varepsilon$ slightly decreased in the $N_{\text {Cybc }}$ phase, it was further enhanced in the following the CybC and $\mathrm{SmC}_{(\mathrm{I})}$ phases. Furthermore, the $\delta \varepsilon$ value remained almost constant throughout the $\mathrm{SmC}_{\text {(II) }}$ phase, in which the molecules were considered to be organized in a quite closepacked structure. Interestingly, the strength of this mode in the $\mathrm{SmC}_{\text {(I) }}$ phase sharply increased with the applied biasing field, as shown in Fig. 6(b). Noticeably, upon applying the bias voltage, the first longitudinal mode $\left(\mathrm{H}_{1}\right)$ was minutely observed at a lower frequency region than $\mathrm{H}_{2}$, which appeared predominantly in the lower homologous compounds without any bias voltage. This can be explained as due to the enhancement of the molecular length in compound $\mathbf{1 / 1 0}$, whereby the terminal chains easily escaped into the surface boundary and produced aliphatic excrescences around the cluster. ${ }^{33}$ Moreover, the combination of steric interaction and dipole-dipole interaction favored orienting the terminal chains parallel to the layer boundary, which allowed interdigitation of the terminal chains. ${ }^{69}$ As a result, the rotation of the molecules about its short axis was hindered in the HT configuration, but imparted a
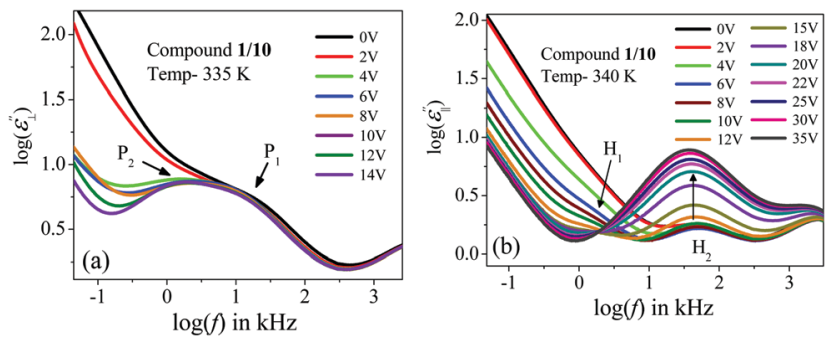

Fig. 6 Variation of the frequency-dependent imaginary part $\left(\varepsilon^{\prime \prime}\right)$ of the complex permittivity with the bias voltage for compound 1/10: in (a) planar and (b) homeotropic alignments. significant influence in the case of the planar-oriented sample. In addition to this, an emergence of the $\mathrm{P}_{2}$ mode was observed in the case of the planar orientation without any bias field. By applying an external field, for both compounds 1/9 and 1/10, the relaxation peak $\left(\mathrm{P}_{2}\right)$ in the planar anchoring $\mathrm{Sm} C_{(\mathrm{I})}$ phase could be clearly resolved, as seen from Fig. 4(a) and 6(a). This mode basically refers to a molecular mode that arises due to a rotation of the molecules around their short axis; again, this mode had an effect on the anti-ferroelectric organization of molecular dipoles. Thus, it can be summarized that mode $\mathrm{P}_{2}$, which was definitively absent in compound $\mathbf{1 / 7}$, appeared in compound $\mathbf{1 / 9}$ after the application of the external field and predominantly found in compound 1/10 without any bias field. This implied that by increasing the chain length, the molecular rotation about the short axis in the HG-configured sample was facilitated gradually. It can be predicted that a further increase in the chain length should exhibit a noticeable appearance of this mode with a greater value of dielectric strength. ${ }^{68,70}$ However, in the case of the HT configuration, the direction of the effective dipole moment diverged from the field direction with increasing the chain length. Additionally, the molecular rotation about the short axis inhibited the enhancement of the chain length. A prominent emergence of the $\mathrm{H}_{1}$ mode in the lower homologs led to an insignificant peak in compound $\mathbf{1 / 1 0}$ that was visible in the spectrum subsequent to the application of bias voltage (Fig. 6(b)). Therefore, the relaxation process exhibited a collective phenomenon in the $\operatorname{Sm} C_{(\mathrm{I})}$ phase, i.e., the relaxation process can be assumed due to the cooperative fluctuation of the dipoles. The associative arrangement of the molecules resulted in an anti-ferroelectric ordering in adjacent layers as reported with other bent-core molecules. ${ }^{70,71}$ However, the $\mathrm{SmC}_{\text {(II) }}$ phase was like a glassy state or solid-like state, which did not respond to the external bias field. For a deeper understanding of the polar ordering for these smectic phases, the fieldinduced switching behavior was also studied, as described below.

\subsection{Electro-optical investigation}

Out of these three investigated compounds, the lower homolog 1/7 had $N_{\text {CybC }}$ and CybC phases where no prominent polarization peak was detected throughout the whole mesomorphic range. On the other hand, the higher homologous compounds (1/9 and 1/10) exhibited two significant polarization peaks in the lower temperature smectic phases and a single polarization peak in the $N_{\text {Cybc }}$ phase, with some extending into the isotropic phase. The obtained current response curves along with the applied AC triangular wave voltage for compounds 1/9 and 1/10 are depicted in Fig. $7(\mathrm{a}-\mathrm{e})$ for both the cell alignments, while the corresponding temperature dependence of the spontaneous polarization $\left(P_{\mathrm{s}}\right)$ is illustrated in Fig. $7(\mathrm{f}$ and $\mathrm{g})$. Simultaneous observations of optical textures in response to the applied field are also represented in Fig. 8 and Fig. S7 (ESI $\dagger$ ).

The switching current response for the planar-aligned compound 1/9 exhibited a broad asymmetrical current peak in the $N_{\text {Cybc }}$ phase, even also in the isotropic phase as represented in Fig. 7(a) at different temperature above and below the $I-N_{\mathrm{CybC}}$ phase transition. However, the appearance of a sharp current peak was observed in the HT configuration, which is shown in 

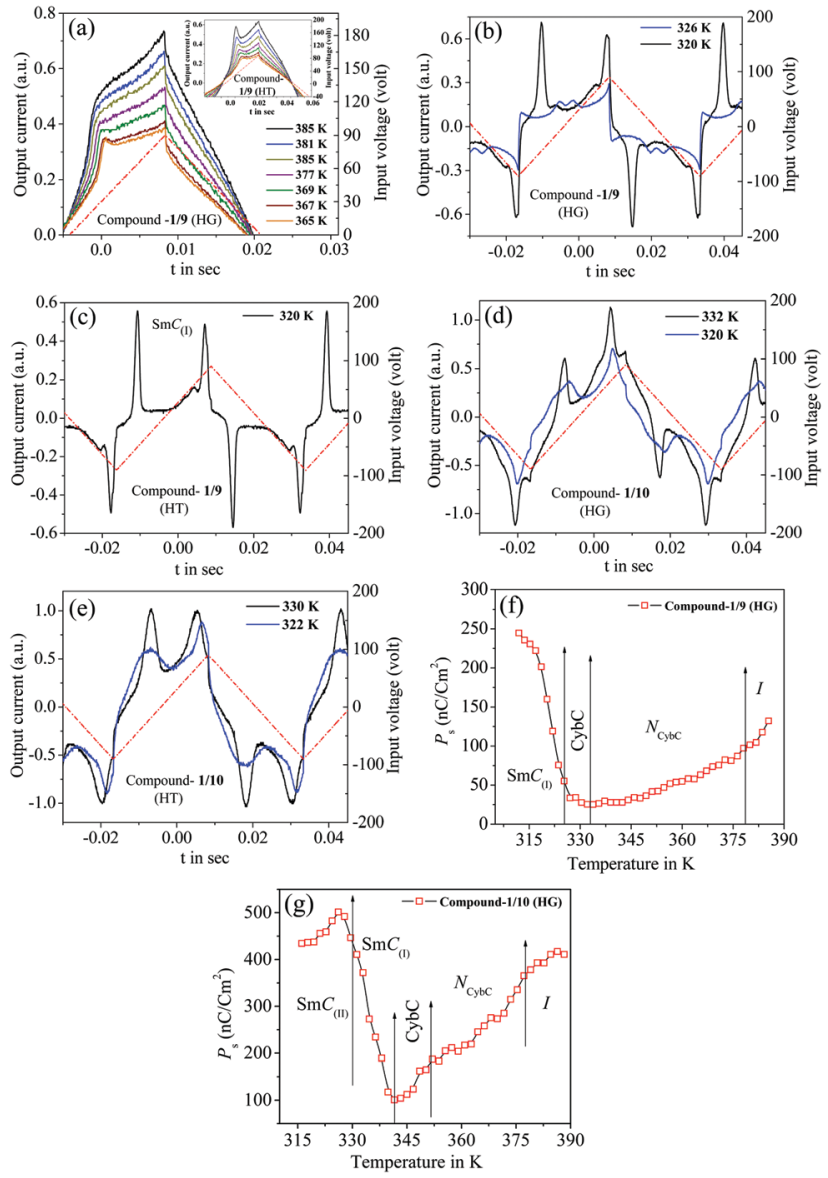

Fig. 7 Switching current response curves of compounds $1 / 9$ and $1 / 10$ for a triangular wave voltage (red dashed line) at different temperatures; $(\mathrm{a}-\mathrm{c}$ ) compound $1 / 9$ in the HG cell, (d) compound $1 / 10$ in the HG cell, (e) compound $\mathbf{1 / 1 0}$ in the HT cell, ( $f$ and $g$ ) temperature-dependent polarization value for compounds $1 / 9$ and $1 / 10$, respectively.

the inset of Fig. 7(a). A similar observation was also noticed in the case of compound $\mathbf{1 / 1 0}$ in the $N_{\mathrm{Cybc}}$ phase for both cell configurations. The area covered by the peak for both the compounds was sufficiently large near the isotropic phase and then slowly diminished in the $N_{\mathrm{Cybc}}$ phase upon lowering the temperature. Thus, the corresponding value of polarization $\left(P_{\mathrm{s}}\right)$ was found to be about $140 \mathrm{nC} \mathrm{cm}{ }^{-2}$ at the isotropic phase for compound 1/9 (see Fig. 7(f)), while compound 1/10 revealed a much higher value $\left(\sim 320 \mathrm{nC} \mathrm{cm}{ }^{-2}\right)$, as represented in Fig. $7(\mathrm{~g})$. With further lowering the temperature, the value of $P$ s gradually decreased throughout the entire $N_{\mathrm{Cybc}}$ phase. It may be concluded that the existence of small clusters consisting of SmC-type polar molecules in the $N_{\mathrm{CybC}}$ phase and even in the isotropic phase induced such a polarization peak. A quite similar type of observation has been reported in four-ring bent-core samples ${ }^{72}$ and in the $\operatorname{Sm} A$ phase of three-ring bentcore compounds. ${ }^{73}$ Therefore, the single peak observed in the switching current indicated that the fluctuation of the polarization vector of these polar cybotactic clusters was induced by the application of the external field, resulting in a ferroelectric-like polar switching ${ }^{72,74,75}$ in the $N_{\mathrm{Cybc}}$ phase. That the peak was due

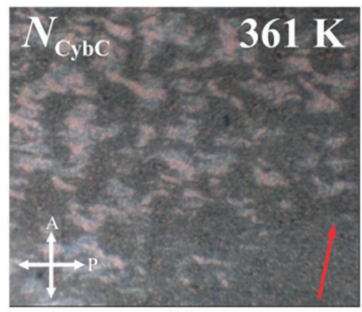

(a)

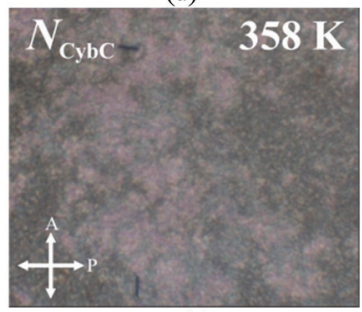

(c)

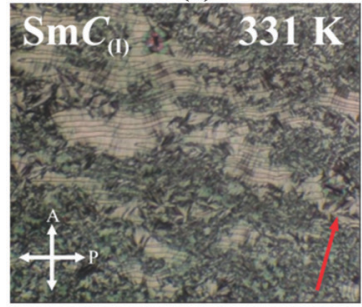

(e)

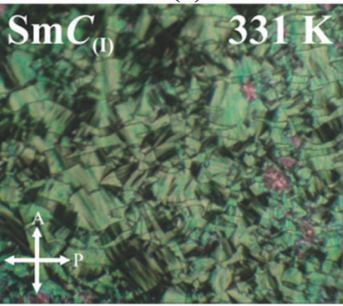

(g)

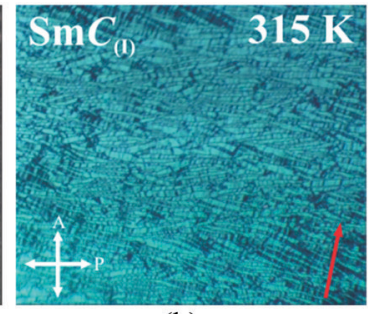

(b)

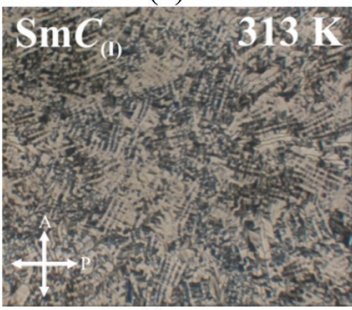

(d)

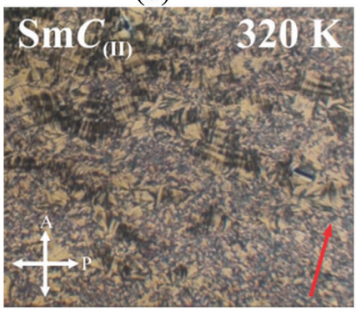

(f)

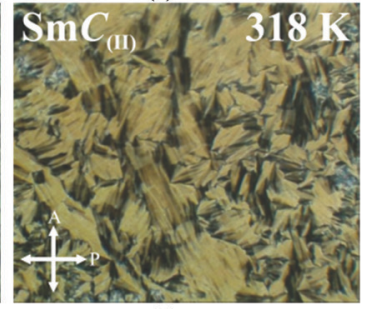

(h)
Fig. 8 Optical textures of compounds $1 / 9$ and $1 / 10$ for an applied square wave AC voltage at different mesophases; ( $a$ and b): compound 1/9 in the HG cell, (c and d): compound 1/9 in the HT cell, (e and f): compound 1/10 in the HG cell, ( $g$ and $h$ ): compound $\mathbf{1 / 1 0}$ in the HT cell. Crossed arrows indicate the direction of the analyzer and polarizer. Red arrows define the rubbing direction in planar orientations.

to polar clusters and not to conductivity was supported by the growing dielectric strength at the $I-N_{\mathrm{CybC}}$ transition. However, the average size of the polar clusters was very small near the isotropic phase, which makes the reorientation of the dipolar axes easier and hence it demonstrated a high value of polarization. ${ }^{27}$ Moreover, as the temperature decreased, the polar clusters increased in size, resulting in an effective increase in viscosity which also restricted the reorientation of the clusters within the $N_{\text {Cybc }}$ phase and hence the polarization value decreased with lowering the temperature. Noticeably, the planar-aligned birefringent texture followed a sharp change upon the application of an electric field $\left(180 \mathrm{~V}_{\mathrm{PP}}, 5 \mathrm{~Hz}\right)$ in the $N_{\text {CybC }}$ phase for both compounds, as shown in Fig. 8(a). When the field was removed, the texture switched back into the initial state within a few milliseconds. A similar observation was also found in the HT cell as well, as seen from Fig. 8(c). Such 
a ferroelectric nature in the nematic phase revealed a good consistency with several experimental reports ${ }^{27,72,76}$ and often a quite higher value of polarization has also been reported in bent-core nematic phases. ${ }^{77}$ Moreover, an irregular streak texture arose in the CybC phase as a result of the applied field for the HG cell, as depicted in Fig. S7 in the ESI. $\dagger$ However, compound 1/10 in the HT cell resembled a broken-fan-shaped texture. Additionally, an appearance of two insignificant peaks in the switching current was found in this phase (blue curve in Fig. 7(b)). With further decreasing the temperature, these two peaks became well distinct and sharp in the $\operatorname{SmC}_{(\mathrm{I})}$ phase, as shown in Fig. 7 (b and c), for both cell configurations. This is the signature of weak anti-ferroelectric ordering of the dipoles in adjacent layers. Nevertheless, the optical texture also showed a considerable change in the field-on state in the $\operatorname{Sm} C_{(\mathrm{I})}$ phase, as represented in Fig. 8(b) for the HG cell and Fig. 8(d) for the HT cell. Although the texture patterns were almost identical in the CybC (compound $\mathbf{1} / \mathbf{9}$ in $\mathrm{HG}$ cell) and $\mathrm{SmC}_{(\mathrm{I})}$ phases (compound $\mathbf{1} / \mathbf{1 0}$ in HT cell), a considerable change in the birefringence was observed between these two phases. However, as the anti-parallel organization of the molecules in the neighboring layers initiated from the CybC phase, the dual insignificant polarization peaks were found to appear from the CybC phase. With lowering the temperature, the obtained polarization value sharply increased to $250 \mathrm{nC} \mathrm{cm}{ }^{-2}$ for the HG configuration in the $\mathrm{Sm}_{(\mathrm{I})}$ phase, as shown in Fig. 7(f). This enhancement of the polarization value has also been reported in some bent-core anti-ferroelectric smectic phases. $^{63,67,78-82}$ Possibly, the steric interaction between the molecules reorients the terminal chains parallel to the layer boundary. Moreover, the strong dipole-dipole interaction also favored the alignment of the molecular dipole moments in adjacent layers in an anti-parallel fashion. The combination of both interactions stabilized the anti-ferroelectric phase. ${ }^{83}$ In addition, two well-distinct sharp peaks of compound 1/10 became initially distorted in the $\mathrm{Sm}_{\text {(II) }}$ phase and finally disappeared at a lower temperature, as represented in Fig. 7(d and e) for the HG and HT cell configurations, respectively. Moreover, the field-on optical texture in the $\mathrm{SmC}_{(\mathrm{II})}$ phase eventually did not return to its initial state when the bias field was switched off, as shown in Fig. 8(f and h) for the HG and HT cells, respectively. This was essentially due to the effect of a more viscous medium with a closely packed nature of the molecules in this phase. Thus the $\mathrm{Sm} C_{(\mathrm{II})}$ phase corresponded to a more solid-like $\mathrm{Sm} C$ phase or a glassy state. The obtained value of $P_{\mathrm{s}}$ increased with the decrease in the temperature, having a maximum value up to $520 \mathrm{nC} \mathrm{cm}^{-2}$ for the $\mathrm{HG}$ configuration in the $\mathrm{SmC}_{(\mathrm{I})}$ phase, while it decreased in the $\mathrm{Sm}_{(\mathrm{II})}$ phase (see Fig. $7(\mathrm{~g})$ ). Surprisingly, the value of polarization for compound $\mathbf{1 / 1 0}$ was found to be greater in the lower temperature smectic phases compared to the second homologous compound $\mathbf{1 / 9}$. This unusual behavior can be explained by considering the deviation of the resultant dipolar contribution with the variation of the chain length. The magnitudes of dipole moment for both compounds were nearly equal, but owing to the elongation of the chain length, a strong component of the effective dipole moment was oriented toward the direction of the field. Recently, similar types of bent-core molecules $(n=6,8,12,14,16,18)$ were synthesized from a 4-cyanoresorcinol aromatic core $\mathrm{e}^{80,84-88}$ with the reversal of the ester linking groups, in which the higher homologous compounds $(n=16,18)$ possessed a non-tilted and non-polar uniaxial $\mathrm{Sm} A$ phase in addition to two uniform tilted $\mathrm{Sm} C$ phases $\left(\mathrm{Sm}_{\mathrm{S}} \mathrm{P}_{\mathrm{F}}\right.$ and $\left.\mathrm{SmC}_{\mathrm{S}} \mathrm{P}_{\mathrm{A}}\right)$. These compounds also exhibited a similar type of bulk polarization behavior, with polarization randomized in the polar domain phases ( $\mathrm{SmCP} \mathrm{P}_{\mathrm{R}}$ phases), showing ferroelectric-like switching domains (replacing the $N_{\text {Cybc }}$ phase) and heliconical $\operatorname{Sm} C_{\mathrm{S}} \mathrm{P}_{\mathrm{F}}$ phases (replacing the CybC phases), followed by anti-ferroelectric $\operatorname{Sm} C_{\mathrm{s}} \mathrm{P}_{\mathrm{A}}$ phases. ${ }^{87,88}$ The field-induced polarization study of the present compounds (1/9 and 1/10) indicated that both lower temperature $\mathrm{SmC}$ phases were polar in nature with anti-ferroelectric ordering of the dipoles and had a sufficiently high value of polarization $\left(P_{\mathrm{s}}\right)$. All these observations were found to be supportive with the conclusions made from the dielectric spectroscopy measurements. Finally, it appeared that the $\mathrm{Sm}_{(\mathrm{I})}$ phase should be designated as $\operatorname{Sm} C_{\mathrm{S}} \mathrm{P}_{\mathrm{A}}$ phase $\left(C_{\mathrm{s}}\right.$ stands for a synclinic-type of molecular organization and $P_{\mathrm{A}}$ corresponds to anti-ferroelectric ordering of the polar orientation in neighboring layers), while the $\operatorname{SmC}($ (II) phase was nothing but a quite solid-like state or close-packed $\mathrm{SmC}$ phase having another version of synclinic-anti-ferroelectric ordering $\left(\mathrm{Sm} C^{\prime}{ }_{\mathrm{S}} \mathrm{P}_{\mathrm{A}}\right.$ phase).

\section{Conclusions}

Three homologous bent-core compounds (1/7, 1/9, and 1/10) derived from 4-cyanoresorcinol bisbenzoates with terminally substituted varying alkyl chains $(n=7,9,10)$ were investigated through precise dielectric spectroscopy and electro-optical measurements. Observations from the dielectric spectroscopy study for the planar and homeotropically aligned compounds revealed that the dielectric modes originated from molecular motion and in some cases it was associated with the local polar ordering of the molecules. Interestingly, the dielectric modes in the $\operatorname{Sm} C_{(\mathrm{I})}$ phase of higher homologs were quite sensitive to the externally applied bias field, indicating an influence of the effective dipole moment of the molecules on these modes, while there was no response in the $N_{\text {Cybc }}$ phase. The field reversal switching polarization study also confirmed the polar contribution of these mesophases. Overall, the measurements clearly explained that the $N_{\text {Cybc }}$ phase of these compounds mostly differed from the usual nematics and exhibited a switchable macroscopic bulk polarization in the direction of the applied electric field, which defines a ferroelectric type of polar ordering. Additionally, the lower temperature $\mathrm{SmC}$ phases $\left(\mathrm{SmC}_{(\mathrm{I})}\right.$ and $\left.\mathrm{Sm} C_{(\mathrm{II})}\right)$ possessed an anti-ferroelectric type of polar ordering in adjacent layers, and the intermediate CybC phase endorsed this ferroelectric to anti-ferroelectric type of transition. Considering all the experimental findings, it was concluded that the $\operatorname{Sm} C_{(\mathrm{I})}$ phase could be designated as $\mathrm{Sm} C_{\mathrm{S}} \mathrm{P}_{\mathrm{A}}$ (synclinic-anti-ferroelectric ordering), while the $\operatorname{Sm} C_{(\mathrm{II})}$ phase 
was a quite solid-like state or close-packed $\operatorname{SmC}$ phase with a similar type of synclinic-anti-ferroelectric ordering. This type of transition character from a rare ferroelectric $N_{\text {Cybc }}$ phase to an anti-ferroelectric $\mathrm{SmC}$ phase is quite interesting among bent-core molecules. All the obtained outcomes can open up a new direction in LC research and supramolecular chemistry by providing a deeper understanding of the structural-property relationship of achiral bent-core molecules. However, these achiral bent-core compounds may be used in electro-optic device technology and could be useful for designing binary or multicomponent mixtures for improving material parameters like induced biaxiality, effective dipole moment, switching time, etc. for practical applications.

\section{Conflicts of interest}

There are no conflicts to declare.

\section{Acknowledgements}

We gratefully acknowledge the financial support from Department of Science and Technology, New Delhi [Project No: EEQ/2017/000829].

\section{References}

1 J. Harden, B. Mbanga, N. Eber, K. Fodor-Csorba, S. Sprunt, J. T. Gleeson and A. Jakli, Phys. Rev. Lett., 2006, 97, 157802.

2 J. Harden, R. Teeling, J. T. Gleeson, S. Sprunt and A. Jakli, Phys. Rev. E: Stat., Nonlinear, Soft Matter Phys., 2008, 78, 031702.

3 C. Bailey, K. Fodor-Csorba, J. T. Gleeson, S. N. Sprunt and A. Jakli, Soft Matter, 2009, 5, 3618.

4 E. Dorjgotov, K. Fodor-Csorba, J. T. Gleeson, S. Sprunt and A. Jakli, Liq. Cryst., 2008, 35, 149.

5 S. Dhara, F. Araoka, M. Lee, K. V. Le, L. Guo, B. K. Sadashiva, K. Song, K. Ishikawa and H. Takezoe, Phys. Rev. E: Stat., Nonlinear, Soft Matter Phys., 2008, 78, 050701.

6 D. Wiant, J. T. Gleeson, N. Eber, K. Fodor-Csorba, A. Jakli and T. Toth-Katona, Phys. Rev. E: Stat., Nonlinear, Soft Matter Phys., 2005, 72, 041712.

7 S. Tanaka, S. Dhara, B. K. Sadashiva, Y. Shimbo, Y. Takanishi, F. Araoka, K. Ishikawa and H. Takezoe, Phys. Rev. E: Stat., Nonlinear, Soft Matter Phys., 2008, 77, 041708.

8 S. Tanaka, H. Takezoe, N. Eber, K. Fodor-Csorba, A. Vajda and A. Buka, Phys. Rev. E: Stat., Nonlinear, Soft Matter Phys., 2009, 80, 021702.

9 M. Kohout, M. Chambers, A. Vajda, G. Galli, A. Domjan, J. Svoboda, A. Bubnov, A. Jakli and K. Fodor-Csorba, Liq. Cryst., 2010, 37, 537.

10 M. Alaasar, M. Prehm, S. Poppe and C. Tschierske, Chem. Eur. J., 2017, 23, 5541.

11 N. Sebastian, S. Belau, A. Eremin, M. Alaasar, M. Prehm and C. Tschierske, Phys. Chem. Chem. Phys., 2017, 19, 5895.
12 D. Guzeller, H. Ocak, B. B. Eran, M. Prehm and C. Tschierske, J. Mater. Chem. C, 2015, 3, 4269.

13 G. Pelzl, S. Diele and W. Weissflog, Adv. Mater., 1999, 11, 707.

14 C. Tschierske and G. Dantlgraber, Pramana, 2003, 61, 455.

15 M. B. Ros, J. L. Serrano, M. R. De la Fuente and C. L. Folcia, J. Mater. Chem., 2005, 15, 5093.

16 R. Amaranta Reddy and C. Tschierske, J. Mater. Chem., 2006, 16, 907.

17 H. Takezoe and Y. Takanishi, Jpn. J. Appl. Phys., 2006, 45, 597.

18 M. Castillo-Vallés, A. Martínez-Bueno, R. Giménez, T. Sierra and M. B. Ros, J. Mater. Chem. C, 2019, 7, 14454-14470.

19 A. Bobrovsky, K. Mochalov, V. Oleinikov, D. Solovyeva, V. Shibaev, Y. Bogdanova, V. Hamplová, M. Kašpar and A. Bubnov, J. Phys. Chem. B, 2016, 120, 5073.

20 S. Patranabish, G. Mohiuddin, N. Begum, A. R. Laskar, S. K. Pal, N. V. S. Rao and A. Sinha, J. Mol. Liq., 2018, 257, 144.

21 S. K. Lee, S. Heo, J. G. Lee, K.-T. Kang, K. Kumazawa, K. Nishida, Y. Shimbo, Y. Takanishi, J. Watanabe, T. Doi, T. Takahashi and H. Takezoe, J. Am. Chem. Soc., 2005, 127, 11085.

22 S. Kumar and A. N. Gowda, Liq. Cryst. Rev., 2015, 3, 99.

23 O. Francescangeli, V. Stanic, S. I. Torgova, A. Strigazzi, N. Scaramuzza, C. Ferrero, I. P. Dolbnya, T. M. Weiss, R. Berardi, L. Muccioli, S. Orlandi and C. Zannoni, Adv. Funct. Mater., 2009, 19, 2592.

24 S. Patranabish, Y. Wang, A. Sinha and A. Majumdar, Phys. Rev. E, 2019, 99, 012703.

25 S. Stojadinovic, A. Adorjan, S. Sprunt, H. Sawade and A. Jákli, Phys. Rev. E: Stat., Nonlinear, Soft Matter Phys., 2002, 66, 060701.

26 D. Wiant, S. Stojadinovic, K. Neupane, S. Sharma, K. FodorCsorba, A. Jakli, J. T. Gleeson and S. Sprunt, Phys. Rev. E: Stat., Nonlinear, Soft Matter Phys., 2006, 73, 030703.

27 O. Francescangeli, V. Stanic, S. Torgova, A. Strigazzi, N. Scaramuzza, C. Ferrero, I. P. Dolbnya, T. M. Weiss, R. Berardi, L. Muccioli, S. Orlandi and C. Zannoni, Adv. Funct. Mater., 2009, 19, 2592.

28 O. Francescangeli and E. T. Samulski, Soft Matter, 2010, 6, 2413.

29 O. Francescangeli, F. Vita, C. Ferrero, T. Dingemans and E. T. Samulski, Soft Matter, 2011, 7, 895.

30 S. Chakraborty, J. T. Gleeson, A. Jákli and S. Sprunt, Soft Matter, 2013, 9, 1817.

31 C. Zhang, M. Gao, N. Diorio, W. Weissflog, U. Baumeister, S. Sprunt, J. T. Gleeson and A. Jákli, Phys. Rev. Lett., 2012, 109, 107802.

32 S. Torgova, S. P. Sreenilayam, Y. P. Panarin, O. Francescangeli, F. Vita, J. K. Vij, E. Pozhidaev, M. Minchenko, C. Ferrero and A. Strigazzi, Phys. Chem. Chem. Phys., 2017, 19, 22946.

33 C. Keith, A. Lehmann, U. Baumeister, M. Prehm and C. Tschierske, Soft Matter, 2010, 6, 1704.

34 D. R. Link, G. Natale, R. Shao, J. E. Maclennan, N. A. Clark, E. Körblova and D. M. Walba, Science, 1997, 278, 1924. 
35 G. Pelzl, S. Diele and W. Weissflog, Adv. Mater., 1999, 11, 707.

36 V. Punjani, G. Mohiuddin, S. Kaur, R. K. Khan, S. Ghosh and S. K. Pal, Chem. Commun., 2018, 54, 3452.

37 M. Cestari, S. Diez-Berart, D. A. Dunmur, A. Ferrarini, M. R. De La Fuente, D. J. B. Jackson, D. O. Lopez, G. R. Luckhurst, M. A. Perez-Jubindo, R. M. Richardson, J. Salud, B. A. Timimi and H. Zimmermann, Phys. Rev. E: Stat., Nonlinear, Soft Matter Phys., 2011, 84, 031704.

38 V. Borshch, Y. K. Kim, J. Xiang, M. Gao, A. Jákli, V. P. Panov, J. K. Vij, C. T. Imrie, M. G. Tamba, G. H. Mehl and O. D. Lavrentovich, Nat. Commun., 2013, 4, 2635.

39 A. H. Price and Á. Buka, Advances in Liquid Crystal Research and Applications, ed. L. Bata, Pergamon Press, New York, Budapest, 1980.

40 H. Kresse, Physical Properties of Liquid Crystals: Nematics, ed. D. A. Dunmur, A. Fukuda and G. R. Luckhurst, Inspec, London, 2001.

41 W. T. Coffey and Y. P. Kalmykov, Adv. Chem. Phys., 2000, 113, 487.

42 C. Krause, H. Yin, C. Cerclier, D. Morineau, A. Wurm, C. Schick, F. Emmerling and A. Schonhals, Soft Matter, 2012, 8, 11115.

43 M. Marik, A. Mukherjee, D. Jana, A. Yoshizawa and B. K. Chaudhuri, Phys. Rev. E: Stat., Nonlinear, Soft Matter Phys., 2013, 88, 012502.

44 K. Kurp, M. Czerwiński, M. Tykarska, P. Salamon and A. Bubnov, J. Mol. Liq., 2019, 290, 111329.

45 H. Takezoe and Y. Takanishi, Smectic Liquid Crystals: antiferroelectric and ferrielectric phases, ed. H. S. Kitzerow and C. Bahr, Springer-Verlag, Berlin, 2001.

46 M. K. Das, B. Barman, B. Das, V. Hamplová and A. Bubnov, Crystals, 2019, 9, 473.

47 M. Rajnak, P. Kopcansky, V. Gdovinova, V. Zavisova, I. Antal, J. Kurimsky, B. Dolnik, J. Jadzyn, N. Tomasovicova, M. Koneracka and M. Timko, Mol. Cryst. Liq. Cryst., 2015, 611, 40 .

48 A. Bubnov, A. Bobrovsky, I. Rychetský, L. Fekete and V. Hamplová, Nanomaterials, 2020, 10, 1498.

49 G. P. Sinha and F. M. Aliev, Phys. Rev. E: Stat., Nonlinear, Soft Matter Phys., 1998, 58, 2001.

50 R. K. Shukla, A. Chaudhary, A. Bubnov and K. K. Raina, Liq. Cryst., 2018, 45, 1672.

51 Á. Buka, N. Éber, K. Fodor-Csorba, A. Jákli and P. Salamon, Phase Transitions, 2012, 85, 872.

52 P. Salamon, N. Éber, Á. Buka, J. T. Gleeson, S. Sprunt and A. Jákli, Phys. Rev. E: Stat., Nonlinear, Soft Matter Phys., 2010, 81, 031711.

53 G. Shanker, M. Prehm, M. Nagaraj, J. K. Vij, M. Weyland, A. Eremin and C. Tschierske, ChemPhysChem, 2014, 15, 1323.

54 G. Shanker, M. Nagaraj, A. Kocot, J. K. Vij, M. Prehm and C. Tschierske, Adv. Funct. Mater., 2012, 22, 1671.

55 A. Chakraborty, M. K. Das, B. Das, A. Lehmann and C. Tschierske, Soft Matter, 2013, 9, 4273.

56 S. Havriliak and S. Negami, J. Polym. Sci., 1966, 14, 99.
57 S. Chakraborty, M. K. Das, A. Bubnov, W. Weissflog, D. Weglowska and R. Dabrowski, J. Mater. Chem. C, 2019, 7, 10530 .

58 S. Ghosh, P. Nayek, S. K. Roy, T. P. Majumder and R. Dabrowski, Liq. Cryst., 2010, 37, 369.

59 A. Pramanik, M. K. Das, B. Das, M. Żurowska and R. Dabrowski, Liq. Cryst., 2015, 42, 412.

60 Y. Jang, V. P. Panov, C. Keith, C. Tschierske and J. K. Vij, Appl. Phys. Lett., 2010, 97, 152903.

61 P. Tadapatri, U. M. Hiremath, C. V. Yelamaggad and K. S. Krishnamurthy, J. Phys. Chem. B, 2010, 114, 1745.

62 P. Tadapatri, K. S. Krishnamurthy and W. Weissflog, Phys. Rev. E: Stat., Nonlinear, Soft Matter Phys., 2010, 82, 031706.

63 L. Kovalenko, M. W. Schröder, R. A. Reddy, S. Diele, G. Pelzl and W. Weissflog, Liq. Cryst., 2005, 32, 857.

64 P. Salamon, N. Eber, A. Buka, J. T. Gleeson, S. Sprunt and A. Jákli, Phys. Rev. E: Stat., Nonlinear, Soft Matter Phys., 2010, 81, 031711.

65 R. Balachandran, V. P. Panov, J. K. Vij, G. Shankar, C. Tschierske, K. Merkel and A. Kocot, Phys. Rev. E: Stat., Nonlinear, Soft Matter Phys., 2014, 90, 032506.

66 Y. Jang, V. P. Panov, A. Kocot, A. Lehmann, C. Tschierske and J. K. Vij, Phys. Rev. E: Stat., Nonlinear, Soft Matter Phys., 2011, 84, 060701.

67 A. Eremin, H. Nádasi, G. Pelzl, S. Diele, H. Kresse, W. Weissflog and S. Grande, PhysChemPhys, 2004, 6, 1290.

68 L. Guo, K. Gomola, E. Grecka, D. Pociecha, S. Dhara, F. Araoka, K. Ishikawa and H. Takezoe, Soft Matter, 2011, 7, 2895.

69 R. A. Reddy and C. Tschierske, J. Mater. Chem., 2006, 16, 907.

70 Y. P. Panarin, S. P. Sreenilayam, J. K. Vij, A. Lehmann and C. Tschierske, Beilstein J. Nanotechnol., 2018, 9, 1288.

71 H. Schlacken, P. Schiller and H. Kresse, Liq. Cryst., 2001, 28, 1235.

72 S. Ghosh, N. Begum, S. Turlapati, S. K. Roy, A. K. Das and N. V. S. Rao, J. Mater. Chem. C, 2014, 2, 425.

73 W. Weissflog, U. Baumeister, M.-G. Tamba, G. Pelzl, H. Kresse, R. Friedmann, G. Hempel, R. Kurz, M. Roos, K. Merzweiler, A. Jakli, C. Zhang, N. Diorio, R. Stannarius, A. Eremin and U. Kornek, Soft Matter, 2012, 8, 2671.

74 G. Shanker, M. Prehm, M. Nagaraj, J. K. Vij, M. Weyland, A. Eremin and C. Tschierske, ChemPhysChem, 2014, 15, 1323.

75 G. Shanker, M. Nagaraj, A. Kocot, J. K. Vij, M. Prehm and C. Tschierske, Adv. Funct. Mater., 2012, 22, 1671.

76 S. Turlapati, R. K. Khan, S. Ghosh, P. Tadapatri, R. Pratibha and N. V. S. Rao, J. Appl. Phys., 2016, 120, 174101.

77 O. Francescangeli, F. Vita and E. T. Samulski, Soft Matter, 2014, 10, 7685.

78 N. Sebastian, S. Belau, A. Eremin, M. Alasar, M. Prehm and C. Tschierske, Phys. Chem. Chem. Phys., 2017, 19, 5895.

79 S. Sreenilayam, M. Nagaraj, Y. P. Panarin, J. K. Vij, A. Lehmann and C. Tschierske, Mol. Cryst. Liq. Cryst., 2012, 553, 140.

80 C. Keith, M. Prehm, Y. P. Panarin, J. K. Vij and C. Tschierske, Chem. Commun., 2010, 46, 3702. 
81 M. Alaasar, M. Prehm, S. Poppe and C. Tschierske, Chem. Eur. J., 2017, 23, 5541.

82 S. P. Sreenilayam, Y. P. Panarin, J. K. Vij, A. Lehmann, M. Poppe and C. Tschierske, Phys. Rev. Mater., 2017, 1, 035604.

83 K. Nishida, M. Čepič, W. J. Kim, S. K. Lee, S. Heo, J. G. Lee, Y. Takanishi, K. Ishikawa, K.-T. Kang, J. Watanabe and H. Takezoe, Phys. Rev. E: Stat., Nonlinear, Soft Matter Phys., 2006, 74, 021704.

84 M. Nagaraj, Y. P. Panarin, J. K. Vij, C. Keith and C. Tschierske, Appl. Phys. Lett., 2010, 97, 213505.
85 S. Sreenilayam, Y. P. Panarin, J. K. Vij, M. Osipov, A. Lehmann and C. Tschierske, Phys. Rev. E: Stat., Nonlinear, Soft Matter Phys., 2013, 88, 012504.

86 Y. P. Panarin, M. Nagaraj, J. K. Vij, C. Keith and C. Tschierske, Europhys. Lett., 2010, 92, 26002.

87 S. P. Sreenilayam, Y. P. Panarin, J. K. Vij, P. Panov, A. Lehmann, M. Poppe, M. Prehm and C. Tschierske, Nat. Commun., 2016, 7, 11369.

88 A. Lehmann, M. Alaasar, M. Poppe, S. Poppe, M. Prehm, M. Nagaraj, S. P. Sreenilayam, Y. P. Panarin, J. K. Vij and C. Tschierske, Chem. - Eur. J., 2020, 26, 4714. 